\title{
Integrin CD11b mediates locus coeruleus noradrenergic neurodegeneration in a mouse Parkinson's disease model
}

\author{
Liyan $\mathrm{Hou}^{1+}{ }^{1}$, Xingyue $\mathrm{Qu}^{2+}$, Xiaofei Qiu${ }^{3,4+}$, Ruixue Huang ${ }^{1}$, Xiulan Zhao ${ }^{4^{*}}$ and Qingshan Wang ${ }^{1,5^{*}}$ (D
}

\begin{abstract}
Background: The loss of locus coeruleus noradrenergic (LC/NE) neurons in the brainstem is reported in multiple neurodegenerative disorders, including Parkinson's disease (PD). However, the mechanisms remain unclear. Strong evidence suggested that microglia-mediated neuroinflammation contributes to neurodegeneration in PD. We recently recognized integrin CD11b, the a-chain of macrophage antigen complex-1 (Mac-1, also called CR3), as a key regulator for microglial activation. However, whether CD11b is involved in LC/NE neurodegeneration in PD remains to be investigated.
\end{abstract}

Methods: LC/NE neurodegeneration and microglial activation were compared between wild type (WT) and CD11b $\mathrm{KO}$ mice after treated with paraquat and maneb, two pesticides that widely used to create PD model. The role of NLRP3 inflammasome in CD11b-mediated microglial dysfunction and LC/NE neurodegeneration was further explored. LC/NE neurodegeneration, microglial phenotype, and NLRP3 inflammasome activation were determined by using Western blot, immunohistochemistry, and RT-PCR technologies.

Results: Paraquat and maneb co-exposure elevated the expressions of CD11b in the brainstem of mice, and CD11b knockout significantly reduced LC/NE neurodegeneration induced by paraquat and maneb. Mitigated microglial activation and gene expressions of proinflammatory cytokines were also observed in paraquat and maneb-treated CD11 $\mathrm{b}^{-/-}$mice. Mechanistically, CD11b-mediated NLRP3 inflammasome activation contributes to paraquat and maneb-induced LC/NE neurodegeneration. Compared with WT controls, CD11b deficiency reduced paraquat and maneb-induced NLRP3 expression, caspase-1 activation, and interleukin-1 $\beta$ production in mice. Furthermore, inhibition of NLRP3 inflammasome by glybenclamide, a sulfonylurea inhibitor of NLRP3 inflammasome, was found to be able to suppress microglial proinflammatory activation and nuclear factor-kB activation induced by paraquat and maneb. Moreover, reduced reactive oxygen species production, NADPH oxidase, and inducible nitric oxide synthase expressions as well as 4-hydroxynonenal and malondialdehyde levels were detected in combined glybenclamide and paraquat and maneb-treated mice compared with paraquat and maneb alone group. Finally, we found that glybenclamide treatment ameliorated LC/NE neurodegeneration and a-synuclein aggregation in paraquat and maneb-treated mice.

(Continued on next page)

\footnotetext{
*Correspondence: zhao.xl@sdu.edu.cn; wangq4@126.com

†Liyan Hou, Xingyue Qu and Xiaofei Qiu contributed equally to this work.

${ }^{4}$ School of Public Health, Cheeloo College of Medicine, Shandong University, Jinan 250012, China

'School of Public Health, Dalian Medical University, Dalian 116044, China

Full list of author information is available at the end of the article
}

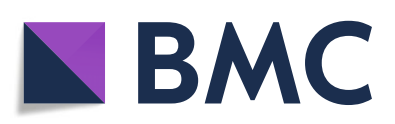

( ) The Author(s). 2020 Open Access This article is licensed under a Creative Commons Attribution 4.0 International License, which permits use, sharing, adaptation, distribution and reproduction in any medium or format, as long as you give appropriate credit to the original author(s) and the source, provide a link to the Creative Commons licence, and indicate if changes were made. The images or other third party material in this article are included in the article's Creative Commons licence, unless indicated otherwise in a credit line to the material. If material is not included in the article's Creative Commons licence and your intended use is not permitted by statutory regulation or exceeds the permitted use, you will need to obtain permission directly from the copyright holder. To view a copy of this licence, visit http://creativecommons.org/licenses/by/4.0/. The Creative Commons Public Domain Dedication waiver (http://creativecommons.org/publicdomain/zero/1.0/) applies to the data made available in this article, unless otherwise stated in a credit line to the data. 
(Continued from previous page)

Conclusion: Our findings suggested that CD11b mediates LC/NE neurodegeneration through NLRP3 inflammationdependent microglial proinflammatory activation in a two pesticide-induced mouse PD model, providing a novel insight into the immune pathogenesis of LC/NE neuronal damage in related disorders.

Keywords: Integrin, Noradrenergic neurodegeneration, NLRP3 inflammasome, Microglial activation, Oxidative stress

\section{Background}

The locus coeruleus noradrenergic (LC/NE) neurons in the upper dorsolateral pontine tegmentum contain more than half of the brain's cellular capacity for synthesizing norepinephrine [1]. Axons of LC/NE neurons are distributed widely throughout the brain, suggesting a prominent role of LC/NE neurons in the normal function of central nervous system (CNS) $[1,2]$. The degeneration of LC/NE neurons is detected in multiple neurodegenerative diseases, such as Alzheimer's disease (AD) and Parkinson's disease (PD) $[3,4]$. Postmortem studies demonstrated that the loss of LC/NE neurons is greater and may be earlier than that of nigral dopaminergic neurons in patients with PD [5, 6]. Furthermore, lesion of LC/NE neurons by $N$-(2-chloroethyl)- $N$-ethyl-2-bromobenzylamine (DSP-4), a selective LC/NE neurotoxicant, exacerbates dopaminergic neurodegeneration and motor deficits in mouse PD models generated by lipopolysaccharide (LPS) or 1-methyl-4-phenyl-1,2,3,6-tetrahydropyridine (MPTP) [7-9], highlighting its importance in the pathogenesis of PD. However, the mechanisms of $\mathrm{LC} / \mathrm{NE}$ neurodegeneration remain unclear.

Integrin $\mathrm{CD} 11 \mathrm{~b}$ is the $\alpha$-chain of macrophage antigen complex-1 (Mac1, also called CD11b/CD18 or CR3) and presents with high levels in innate immune cells, including microglia [10-12]. Although CD11b is well-documented to regulate phagocytosis and migration of microglial cells $[11,13]$, studies revealed that CD11b can also recognize a variety of stimuli to mediate neuroinflammation and neurodegeneration [14-16]. Zhang et al. reported that microglial CD11b is critical for the neurotoxicity induced by $\beta$ amyloid $(A \beta)$, the main component of senile plaques in $A D$, since $C D 11 b$ knockout significantly attenuates $A \beta$ induced microglial activation, superoxide production, and neurodegeneration in both in vitro and in vivo conditions [17]. Furthermore, Czirr et al. reported that ablation of $\mathrm{CD} 11 \mathrm{~b}$ in human amyloid precursor protein-transgenic mice decreased accumulation of $A \beta$ in the brain [18]. In a mouse stroke model induced by middle cerebral artery occlusion (MCAO), genetic inactivation of CD11b also reduced blood brain barrier permeability and infarct volume [19]. We recently found that $\alpha$-synuclein, a protein that accumulates in Lewy bodies and Lewy neurites in PD, interacts with $\mathrm{CD} 11 \mathrm{~b}$ to stimulate microglial activation and superoxide production in microglial cells [20]. More importantly, CD11b deficiency markedly suppresses microglial activation and dopaminergic neurodegeneration in paraquat and maneb-induced mouse PD model [21], suggesting that CD11b activation is involved in the pathogenesis of PD. However, whether CD11b contributes to LC/ NE neurodegeneration remains to be investigated.

In the present study, we aimed to investigate the role of CD11b in LC/NE neurodegeneration by using a mouse PD model induced by paraquat and maneb co-exposure (referred to subsequently as $P+M)$. We found that $P+M$ elevated CD11b expression and genetic deletion of CD11b in mice significantly ameliorated $\mathrm{P}+\mathrm{M}$-induced $\mathrm{LC} / \mathrm{NE}$ neurodegeneration. Mechanistically, CD11b-mediated NLRP3 inflammasome activation and subsequent microglial proinflammatory activation as well as oxidative damage contributed to LC/NE neurodegeneration in paraquat and manebtreated mice. Our findings provide a novel insight for the pathogenesis of LC/NE neurodegeneration in PD.

\section{Materials and methods}

\section{Animal dosing}

Male wild type (WT, C57BL/6) and CD11b ${ }^{-/-}$mice were randomly divided into 2 groups, i.e., control, $\mathrm{P}+\mathrm{M}$. Mice in $\mathrm{P}+\mathrm{M}$ group were administrated (i.p) with combined paraquat $(10 \mathrm{mg} / \mathrm{kg})$ and maneb $(30 \mathrm{mg} / \mathrm{kg})$ for consecutive 6 weeks (twice per week) according to our previous report [22]. Mice in control group received an equivalent volume of $0.9 \%$ saline. Housing and breeding of animals were performed strictly with Dalian Medical University's Guide for the Care and Use of Laboratory Animals. All animal procedures and their care were carried out in accordance the National Institute of Health Guide for the Care and Use of Laboratory Animals and were approved by the Institutional Animal Care and Use Committee of Dalian Medical University.

\section{Glybenclamide treatment}

Glybenclamide $(1 \mathrm{mg} / \mathrm{kg})$ was administrated to mice 30 min before $\mathrm{P}+\mathrm{M}$ co-exposure for consecutive 6 weeks (twice per week). The chosen of dose of glybenclamide was based on previous report [23].

\section{Immunohistochemistry}

Immunohistochemistry was performed as described previously $[24,25]$. Briefly, mice ( $n=6-8$ in each group) were perfusion using $4 \%$ paraformaldehyde, and the brains were sectioned into coronal slices $(30 \mu \mathrm{m})$. The sections were stained with primary antibodies targeting 
tyrosine hydroxylase (TH, 1:1000; EMD Millipore Corporation, Billerica, MA, USA) or ionized calcium binding adaptor molecule-1 (Iba1, 1:2000; Wako Chemicals, Richmond, VA, USA), followed by treatment with biotin-labeled secondary antibodies and Vectastain ABC reagents. The bound complex was visualized using 3,3'diaminobenzidine. The densities of the Iba- 1 in the LC were measured using the Image software based on our previous method [26].

The number of $\mathrm{TH}$-immunoreactive (THir) neurons in the LC region was visually counted under a microscope ( $\times 200)$, as described previously [27]. The boundary of LC was outlined under magnification of the $\times 4$ objective as per the atlas [28]. Every three sections from the rostral of a series of 36 sections that cover the entire extent of LC were selected for counting [22].

\section{Real-time PCR analysis}

Mice ( $n=5-6$ in each group) were perfused with PBS only and then scarified. The brainstems of mice were quickly dissected based on the atlas [28] and then were equally divided into two parts for real-time PCR and biochemical analysis, respectively, as described previously $[29,30]$. Total RNA was extracted with RNeasy Mini kit (Qiagen, Germantown, MD, USA) and reverse transcribed with an oligodT primer. Real-time PCR amplification was performed using SYBR Premix Ex Taq $^{\text {TM }}$ II (Takara Bio Inc. Kusatsu, Shiga, Japan) and Takara Thermal Cycler Dice ${ }^{\text {Tu }}$ Real Time System according to manufacturer's protocols. The PCR conditions were $95{ }^{\circ} \mathrm{C}$ for $10 \mathrm{~s}, 55^{\circ} \mathrm{C}$ for $30 \mathrm{~s}$, and $72{ }^{\circ} \mathrm{C}$ for $30 \mathrm{~s}$ for 40 cycles. Relative mRNA gene levels were normalized to the GAPDH mRNA level, and relative expressions were determined by the comparative $\mathrm{Ct}$ method [22].

\section{Western blot analysis}

The brainstem samples ( $n=6$ in each group) were homogenized with a homogenizer $(10,000-15,000 \mathrm{rpm}, 10$ s) at $4{ }^{\circ} \mathrm{C}$ in cold RIPA lysis buffer containing inhibitors of proteinase and phosphatase as described previously $[21,31]$. After centrifugation at $4{ }^{\circ} \mathrm{C}(3000 \mathrm{rpm}, 10 \mathrm{~min})$, the supernatant was separated, and protein content was estimated by using commercial $\mathrm{BCA}^{\mathrm{TM}}$ Protein assay Kits (Pierce Biotechnology, Inc.). Equal amounts of protein were separated by $4-12 \%$ Bis-Tris-polyacrylamide electrophoresis gel and transferred to polyvinylidenedifluoride membranes. The membranes were incubated with primary antibodies against NLRP3 (1:1,000; Abcam, Cambridge, MA, USA), caspase-1 (1:1,000; Abcam, Cambridge, MA, USA and 1:500, Santa Cruz Biotechnology, Dallas, TX, USA), interleukin-1 $\beta$ (Il-1 $\beta$; Santa Cruz Biotechnology, Dallas, TX, USA), inducible nitric oxide synthase (iNOS, BD Transduction Laboratories, San Jose,

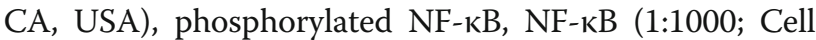

Signaling Technology, Danvers, MA, USA), 4hydroxynonenal (4-HNE, 1:1000; Abcam, Cambridge, MA, USA), $\mathrm{p} 47^{\text {phox }}$ (1:1000; EMD Millipore, Temecula, CA, USA), gp91 ${ }^{\text {phox }}$ (1:1000; BD Transduction Laboratories, San Jose, CA, USA), and GAPDH (Abcam, Cambridge, MA, USA) overnight at $4{ }^{\circ} \mathrm{C}$ and followed by horseradish peroxidase-linked anti-rabbit IgG for $2 \mathrm{~h}$ at $25{ }^{\circ} \mathrm{C}$. ECL reagents (Biological Industries, Cromwell, CT, USA) were used as a detection system.

\section{IL-1 $\beta$ assay}

The brainstem tissues were homogenized and centrifuged at $10,000 \times g$ for $10 \mathrm{~min}$ at $4{ }^{\circ} \mathrm{C}$. The levels of IL-1 $\beta$ (lengton Inc, Shanghai, China) in the collected supernatant were determined spectrophotometrically respectively with commercial kits according to the manufacturer's instructions.

\section{Statistical analysis}

All values were expressed as mean \pm SEM. ShapiroWilk and Bartlett's tests were used to analyze the normal distributions and equal variances, respectively. Statistical analysis between two groups was performed using Student's $t$ test when the distribution was normal; otherwise, the non-parametric test was used. The statistical comparisons for multiple groups were analyzed by oneway or two-way ANOVA (treatment/genotype as the independent factors) when the distribution was normal; otherwise, the non-parametric test was used. When ANOVA showed significant differences, pair-wise comparisons between means were tested by Tukey's post hoc testing for variance homogeneity data or Tamhane's T2 testing for variance data. $p<0.05$ was considered to be statistical significant.

\section{Results}

CD11b mediates $\mathrm{P}+\mathrm{M}$-induced LC/NE neurodegeneration in mice

To determine whether $\mathrm{CD} 11 \mathrm{~b}$ contributes to $\mathrm{LC} / \mathrm{NE}$ neurodegeneration in $\mathrm{PD}$, we initially determined the expressions of CD11b in P + M-induced mouse PD model. Immunohistochemistry was performed by using antiCD11b antibody in saline and P + M-treated mice. Results showed that compared with vehicle controls, $\mathrm{P}+$ $M$ exposure significantly increased the expressions of CD11b in the brainstem of mice (Fig. 1a). Quantitative analysis of $\mathrm{CD} 11 \mathrm{~b}$ density supported these observations (Wilcoxon $W=45.000, Z=-3.576, p<0.01$; Fig. 1a). The elevated expressions of CD11b by $\mathrm{P}+\mathrm{M}$ treatment were further confirmed by Western blot $(t=-7.220, p$ $<0.01$; Fig. 1b).

Next, CD11b-deficient mice were used to determine whether CD11b plays a role in $\mathrm{P}+\mathrm{M}$-induced $\mathrm{LC} / \mathrm{NE}$ neurodegeneration. Immunohistochemical staining using anti-TH antibody was performed in the LC, and the 


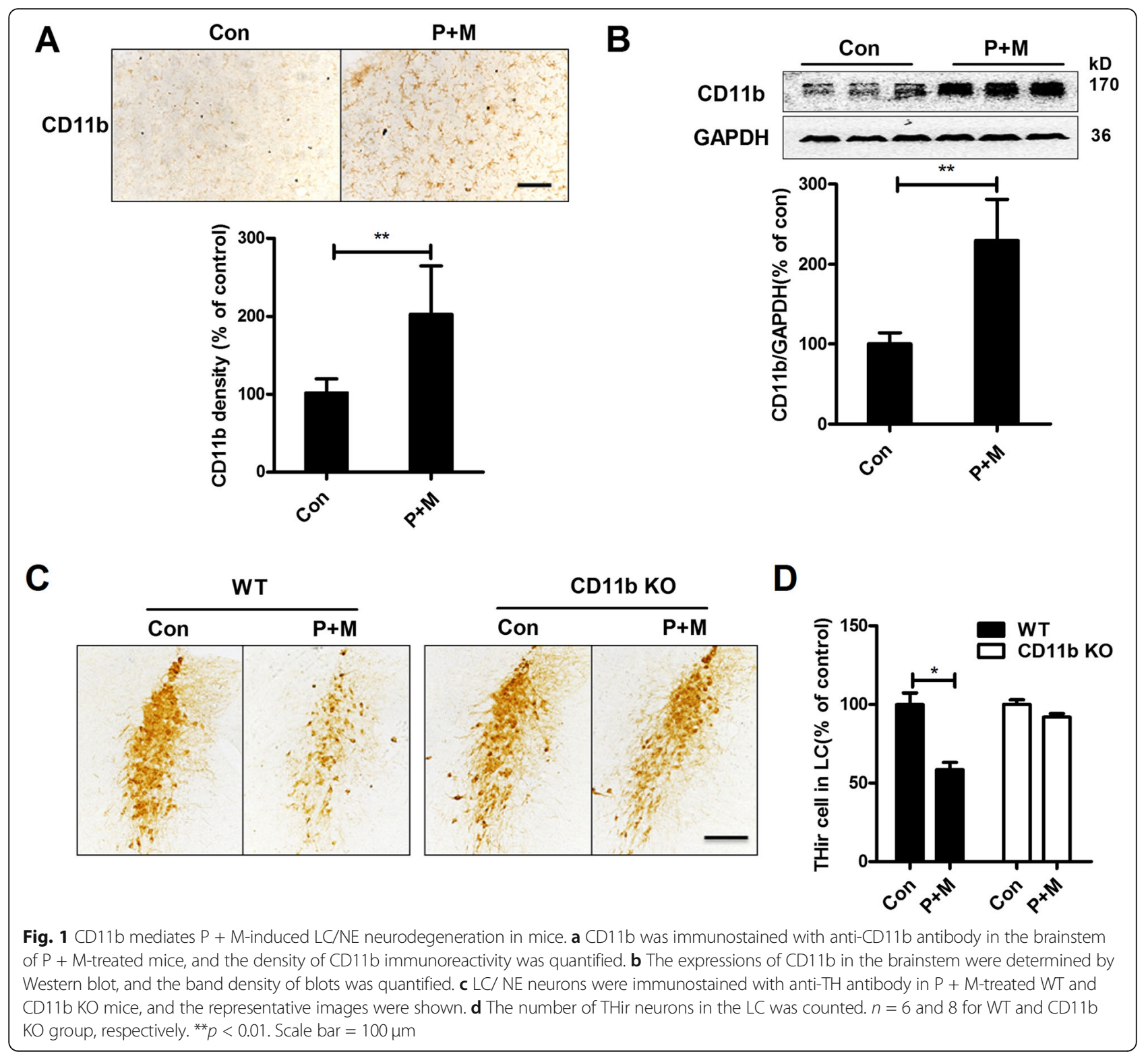

number of THir neurons was counted. Consistent with our previous reports [22, 30], a significant decrease of THir neurons in the LC in WT mice after 6 weeks of P + $\mathrm{M}$ exposure was observed, indicating LC/NE neurodegeneration $\left(F_{(3,24)}=16.532, p<0.01\right.$; Fig. $1 \mathrm{c}$ and d). Interestingly, $\mathrm{P}+\mathrm{M}$-induced loss of $\mathrm{LC} / \mathrm{NE}$ neurons was

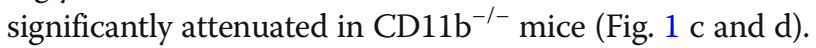

\section{CD11b deficiency suppresses $\mathrm{P}+\mathrm{M}$-induced microglial activation and gene expression of proinflammatory factors in mice}

To verify whether the attenuated LC/NE neurotoxicity in $\mathrm{P}+\mathrm{M}$-treated $\mathrm{CD} 11 \mathrm{~b}^{-/-}$mice was associated with reduced microglial activation, microglia were stained with antibody against Iba-1, a marker of known to upregulate during microglial activation. Activated microglia exhibiting hypertrophied morphology, elevated Iba-1 expression, and increased density of Iba- 1 immunostaining in the LC were observed in P + M-treated WT mice (Fig. 2 $\mathrm{a}$ and $\mathrm{b})$. In contrast, microglia in $\mathrm{P}+\mathrm{M}$-injected $\mathrm{CD}_{11} \mathrm{~b}^{-/-}$mice revealed ramified resting morphology and similar levels of Iba-1 expression as observed in saline-injected CD11b ${ }^{-/-}$mice (Fig. 2 a and b).

Activated microglia will release proinflammatory factors, resulting in neuronal damage. The gene expressions of TNF $\alpha$ and IL-1 $\beta$ in the brainstem of both $\mathrm{CD}_{11 \mathrm{~b}^{-/-}}$ and WT mice after $\mathrm{P}+\mathrm{M}$ treatment were determined. Figure $2 \mathrm{c}$ and $\mathrm{d}$ showed that $\mathrm{P}+\mathrm{M}$ exposure greatly increased gene expressions of TNF $\alpha$ (Kruskal Wallis $H$ test: $H(3)=9.887, p=0.02$ ) and IL-1 $\beta$ (Kruskal Wallis $H$ 


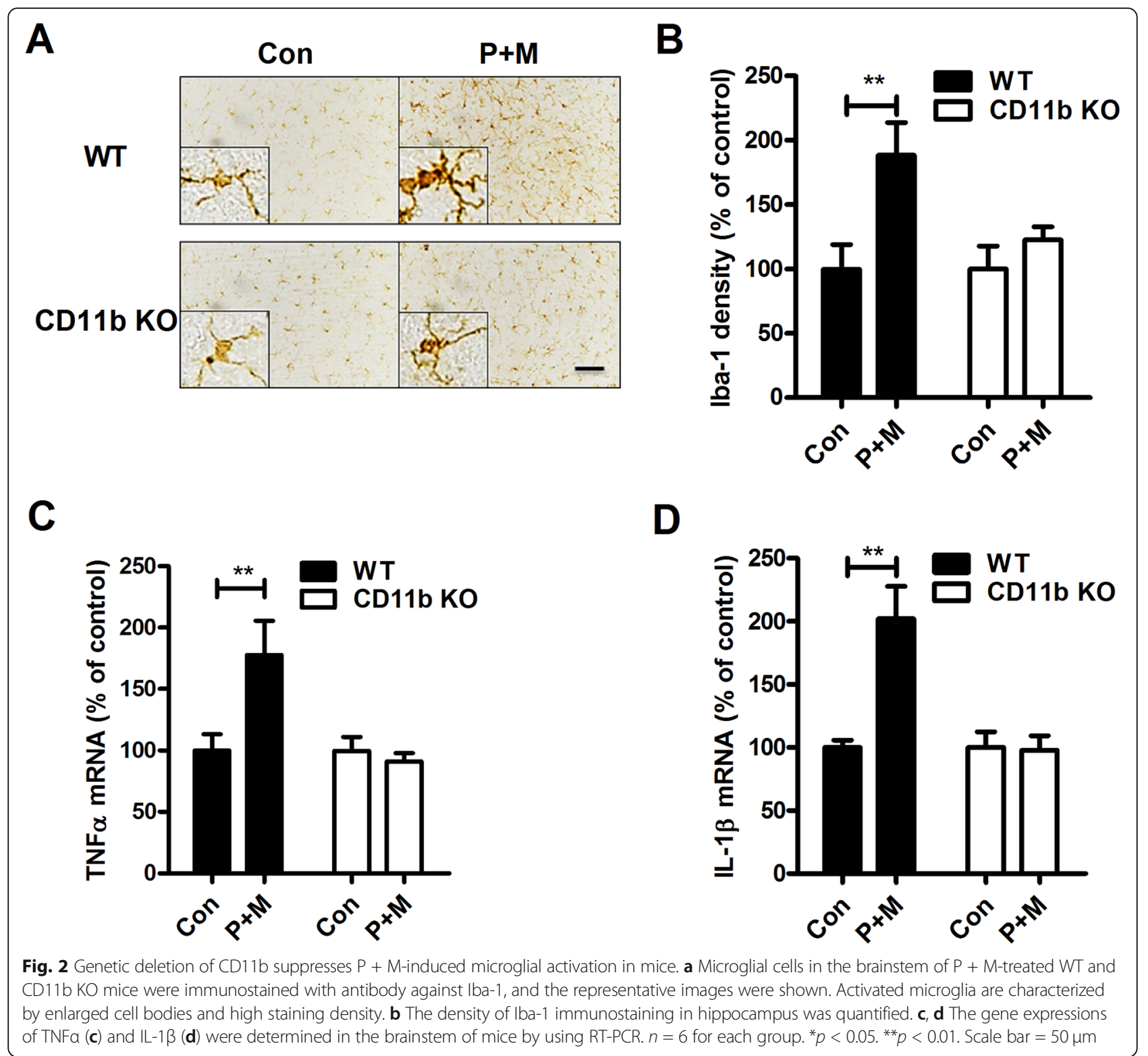

test: $\mathrm{H}(3)=12.492, p=0.006)$ in WT mice, but their expressions were significantly attenuated in $\mathrm{CD}_{11} \mathrm{~b}^{-/-}$ mice. Together, these data demonstrate that CD11b contributes to $\mathrm{P}+\mathrm{M}$-induced LC/NE neurodegeneration by augmenting microglia-mediated neuroinflammation.

\section{CD11b deficiency diminishes $\mathrm{P}+\mathrm{M}$-induced NLRP3 inflammasome activation in mice}

Previous studies indicated that the activation of nod-like receptor family pyrin domain-containing 3 (NLRP3) inflammasome is a key factor to regulate microglial activation in neurodegenerative diseases [32, 33]. To explore whether NLRP3 inflammasome is involved in CD11bmediated microglial activation, the effects of CD11b on activation of NLRP3 inflammasome were determined in mice treated with $\mathrm{P}+\mathrm{M}$. As illustrated in Fig. $3 \mathrm{a}-\mathrm{f}, \mathrm{P}+$ $\mathrm{M}$ exposure resulted in elevation of NLRP3 expression $\left(F_{(3,20)}=15.897, p<0.01\right)$, caspase-1 activation $\left(F_{(3,20)}=\right.$ $21.449, p<0.01)$ and IL-1 $\beta$ maturation $\left(F_{(3,20)}=15.465\right.$, $p<0.01)$ in the brainstem of WT mice, although the expressions of pro-capase- 1 and pro-IL- $1 \beta$ remained unchanged. ELISA assay also showed an increased content of IL-1 $\beta$ in $\mathrm{P}+\mathrm{M}$-treated WT mice compared with vehicle controls (Kruskal Wallis $H$ test: $H(3)=8.002, p=$ 0.046; Fig. 3g), indicating NLRP3 inflammasome activation. In contrast, in CD11 $\mathrm{b}^{-1-}$ mice, $\mathrm{P}+\mathrm{M}$-induced activation of NLRP3 inflammasome was markedly reduced by showing similar levels of NLRP3 expression, caspase1 activation, and IL-1 $\beta$ production between $\mathrm{P}+\mathrm{M}$ treated mice and vehicle controls (Fig. 3a-g). 


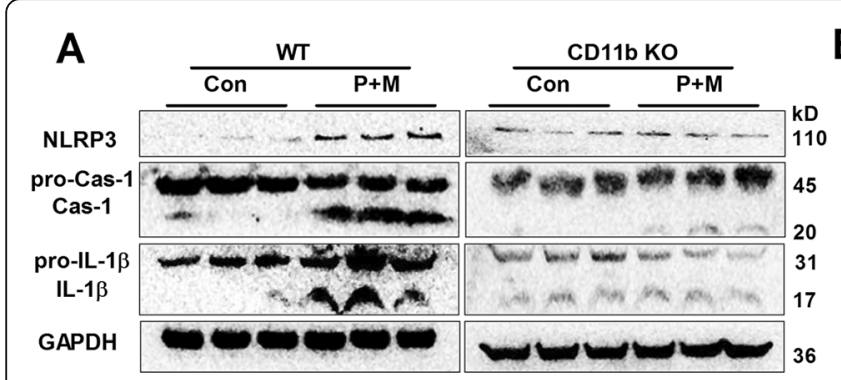

D

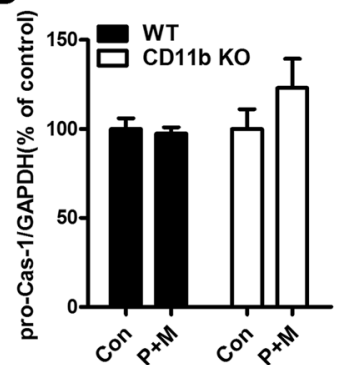

$\mathbf{E}$

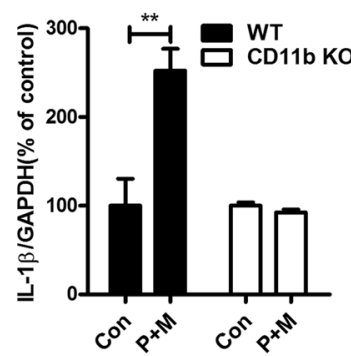

B

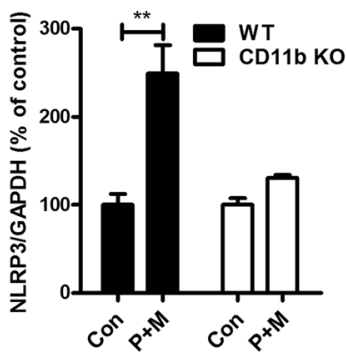

$\mathbf{F}$

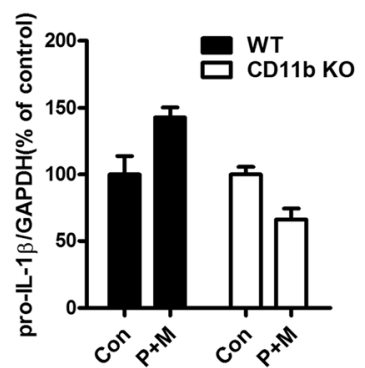

C

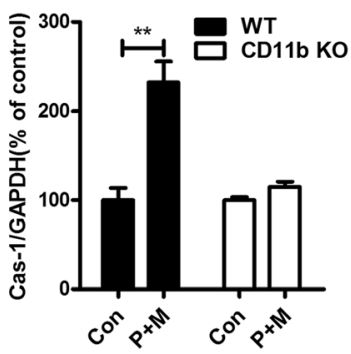

G

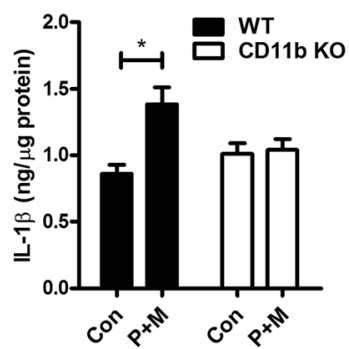

Fig. 3 Genetic deletion of CD11b attenuates P + M-induced activation of NLRP3 inflammasome in mice. a The expressions of NLRP3, pro-caspase-1, caspase-1 p10, pro-lL-1 $\beta$, and IL-1 $\beta$ in the brainstem of P + M-treated WT and CD11b KO mice were detected by using Western blot, and the representative blots were shown. GAPDH was used as an internal control. b-f The band density of NLRP3 (b), pro-caspase-1 (c), caspase-1 (d), pro-lL-1 $\beta$ (e), and mature IL-1 3 (f) was quantified. $n=6$ for each group. $\mathbf{g}$ The levels of IL-1 $\beta$ in the brainstem of mice were measured by using a commercial ELISA kit. ${ }^{*} p<0.05 .{ }^{* *} p<0.01$

Inhibition of NLRP3 inflammasome by glybenclamide blocks $\mathrm{P}+\mathrm{M}$-induced microglial proinflammatory activation

Subsequently, we determined the effects of inhibition of NLRP3 inflammasome on P + M-induced microglial activation. Glybenclamide, a widely used sulfonylurea inhibitor of NLRP3 inflammasome, was administrated to mice prior to $\mathrm{P}+\mathrm{M}$ treatment. Figure 4 revealed that glybenclamide treatment significantly decreased NLRP3 expression $\left(F_{(2,15)}=18.041, p<0.01\right)$, caspase- 1 activation $\left(F_{(2,15)}\right.$ $=39.052, p<0.01$ ), and IL-1 $\beta$ production (Kruskal Wallis $H$ test: $H(2)=15.158, p=0.001)$ in the brainstem in $\mathrm{P}+$ $\mathrm{M}$-treated mice, indicating inhibition of NLRP3 inflammasome by glybenclamide. Then, microglial activation was examined in $\mathrm{P}+\mathrm{M}$-treated mice with or without glybenclamide pre-treatment. As seen in Fig. 5a, microglia in the $\mathrm{LC}$ in $\mathrm{P}+\mathrm{M}$-treated mice displayed hypertrophic morphology and increased Iba-1 immunostaining density, which was significantly recovered by glybenclamide. Analysis of Iba-1 immunostaining density and protein expression supported the morphological observation (Fig. $5 \mathrm{a}$ and b).

Microglial activation can be polarized into "classical" (M1) and "alternative" (M2) phenotypes that produce detrimental and beneficial effects, respectively [34]. qPCR analyses revealed that glybenclamide suppressed transcription levels of M1 genes iNOS (Kruskal Wallis $H$ test: $H(2)=7.833, p=0.02)$ and $\operatorname{TNF} \alpha\left(F_{(2,14)}=5.954, p\right.$ $=0.013$ ) but failed to interfere with M2 genes (Arg-1 and YM-1) in the brainstem in P + M-treated mice, indicating that glybenclamide blocks microglial proinflammatory activation (Fig. $5 \mathrm{c}$ and d).

\section{Glybenclamide mitigates $\mathrm{P}+\mathrm{M}$-induced activation of NF- кB pathway}

Strong evidence suggested that the activation of NF-kB signaling is essential for proinflammatory factors production and microglial proinflammatory activation [35, 36]. Consistent with microglial activation, $\mathrm{P}+\mathrm{M}$ exposure elevated the levels of phosphorylated NF- $\mathrm{B}$ in the brainstem of mice compared with vehicle controls. Interestingly, glybenclamide treatment significantly reduced $\mathrm{P}+\mathrm{M}$ induced NF- $\mathrm{B}$ phosphorylation in mice $\left(F_{(2,15)}=10.544\right.$, $p=0.001$; Fig. 6 a and b). Glybenclamide failed to interfere with the expressions of total NF- $\mathrm{BB}$, although $\mathrm{P}+\mathrm{M}$ also elevated the total levels of NF-kB in mice (Fig. 6 a and c). These results suggested that inhibition of NLRP3 inflammasome by glybenclamide decreased activation of NF- $\mathrm{KB}$ signaling in $\mathrm{P}+\mathrm{M}$-related mice.

\section{Glybenclamide mitigates $\mathrm{P}+\mathrm{M}$-induced oxidative stress in mice}

Microglial activation, especially proinflammatory activation, produces not only proinflammatory cytokines but also ROS, resulting in oxidative stress in microenvironment $[25,37]$. In agreement with inhibition of microglial proinflammatory activation, glybenclamide treatment 


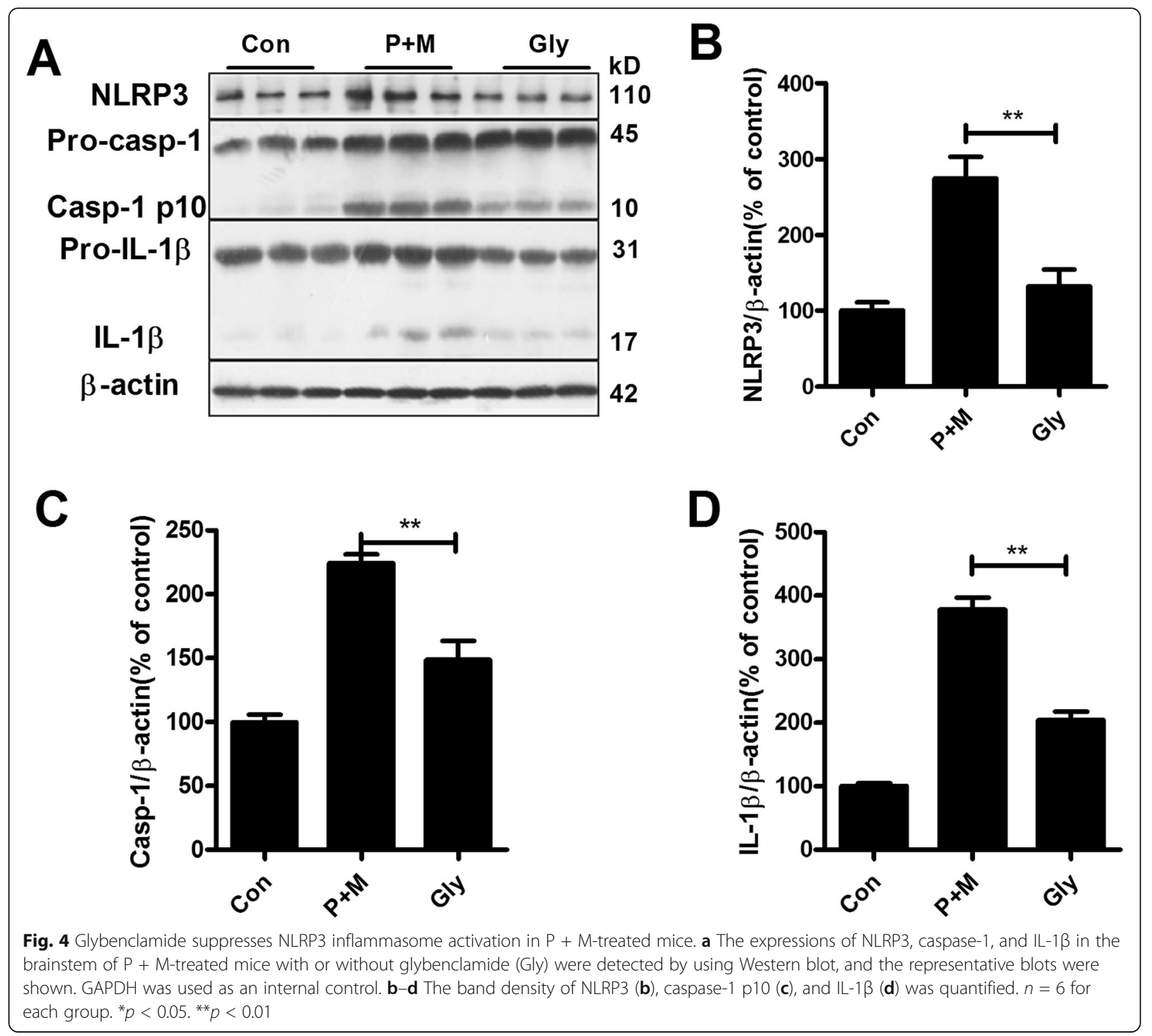

decreased the production of ROS in the brainstem of $\mathrm{P}$ + M-injected mice (Kruskal Wallis $H$ test: $H(2)=7.538$, $p=0.023$; Fig. 7a). $\mathrm{P}+\mathrm{M}$-induced increase of contents of 4-hydroxynonenal (4-HNE), one marker for oxidative stress, was also mitigated by glybenclamide in mice (Fig. $7 \mathrm{~b}$ and $\mathrm{c}$ ).

NADPH oxidase (NOX2) and iNOS are two main enzymes responsible for oxidative stress in microgliamediated neuroinflammation [38, 39]. To determine whether NOX2 and iNOS are involved in the inhibitory effects of glybenclamide on oxidative stress, the expressions of NOX2 and iNOS were determined. As shown in Fig. $7 \mathrm{~d}$ and e, $\mathrm{P}+\mathrm{M}$ exposure elevated the expressions of $\mathrm{p} 47^{\text {phox }}\left(F_{(2,15)}=20.834, p<0.01\right)$ and $\mathrm{gp} 91^{\text {phox }}$ $\left(F_{(2,15)}=61.589, p<0.01\right)$, two subunits of NOX2, as well as $\operatorname{iNOS}\left(F_{(2,15)}=46.929, p<0.01\right)$ in the brainstem of mice, which were significantly reduced by glybenclamide.

\section{Glybenclamide ameliorates $\mathrm{P}+\mathrm{M}$-induced LC/NE} neurodegeneration and a-synuclein aggregation in mice To determine whether inhibition of NLRP3 inflammasome by glybenclamide was able to protect LC/NE neurons, immunohistochemistry using anti-TH antibody was performed in LC, and the number of THir neurons was recorded in $\mathrm{P}+\mathrm{M}$-intoxicated mice with or without glybenclamide pre-treatment. As shown in Fig. 8a, compared with $\mathrm{P}+\mathrm{M}$ alone group, a high number of THir neurons were observed in combined glybenclamide and P + M-treated mice. Quantitative analysis revealed a $25.4 \%$ protection afforded by glybenclamide compared with $\mathrm{P}+\mathrm{M}$ alone group $\left(F_{(2,15)}=8.331, p=0.004\right.$; Fig. 


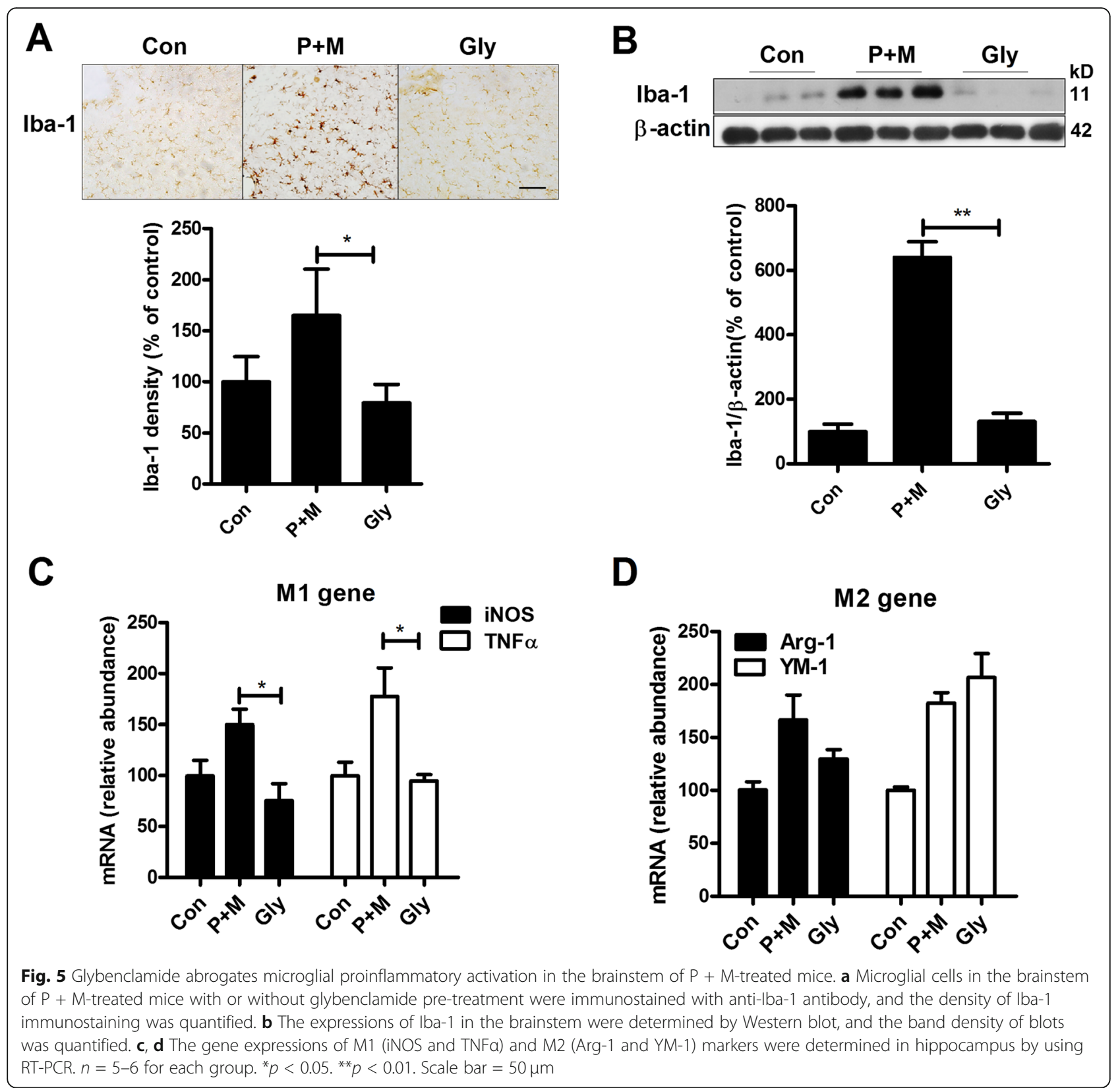

8b). In agreement with LC/NE neuroprotection, glybenclamide also reduced $\alpha$-synuclein aggregation in $\mathrm{P}+\mathrm{M}$ treated mice. Western blot analysis revealed that glybenclamide significantly decreased the expressions of both monomeric (Kruskal Wallis $H$ test: $H(2)=8.187, p=$ $0.017)$ and oligomeric $\alpha$-synuclein $\left(F_{(2,15)}=14.788, p<\right.$ 0.01 ) in the brainstem of mice treated with $\mathrm{P}+\mathrm{M}$ (Fig. $8 \mathrm{c}$ and d). Notably, although no other band was detected, we still cannot exclude the possibility that glybenclamide could reduce expressions of dimer, trimer, or tetramer of $\alpha$-synuclein. The reasons might be due to the low levels of these forms of $\alpha$-synuclein that beyond our detect limitation in our conditions.

\section{Discussion}

Beyond nigral dopaminergic neurodegeneration, patients with PD also display neuronal damage in multiple brain regions, including LC $[1,4]$. The degeneration of LC/NE neurons is well-documented in PD, which might be one of the reasons for the appearance of non-motor symptoms in patients [1]. Consistent with that of PD patients, we recently found the loss of LC/NE neurons in $\mathrm{P}+\mathrm{M}$ and LPS-intoxicated mice [7, 22, 30], two widely used mouse PD models. Furthermore, pre-lesion of LC/NE neurons by DSP-4 significantly exacerbates neurodegeneration in the subsantia nigra, hippocampus, and cortex, which were associated with aggravated motor and non-motor 

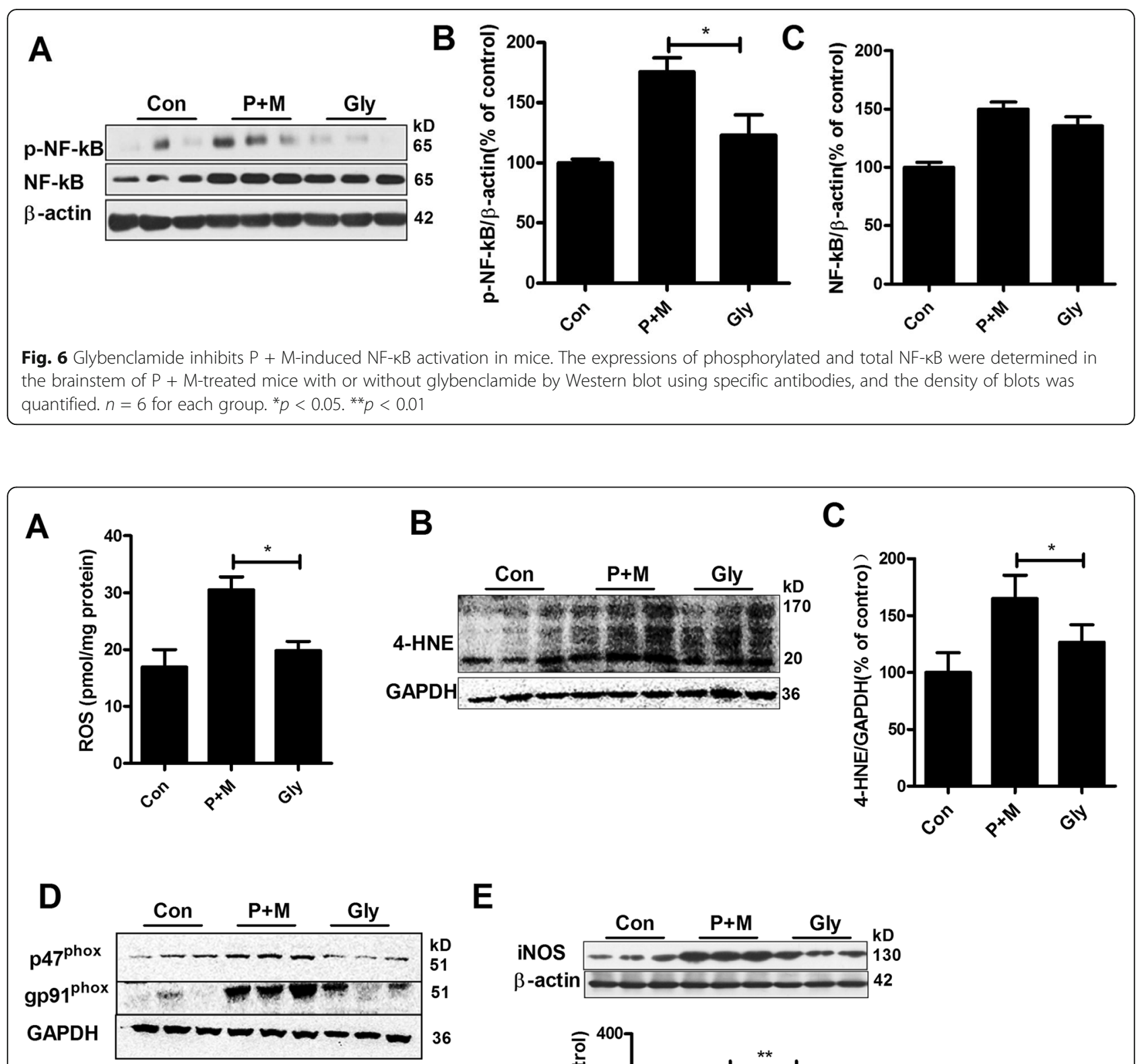

$\mathbf{E}$
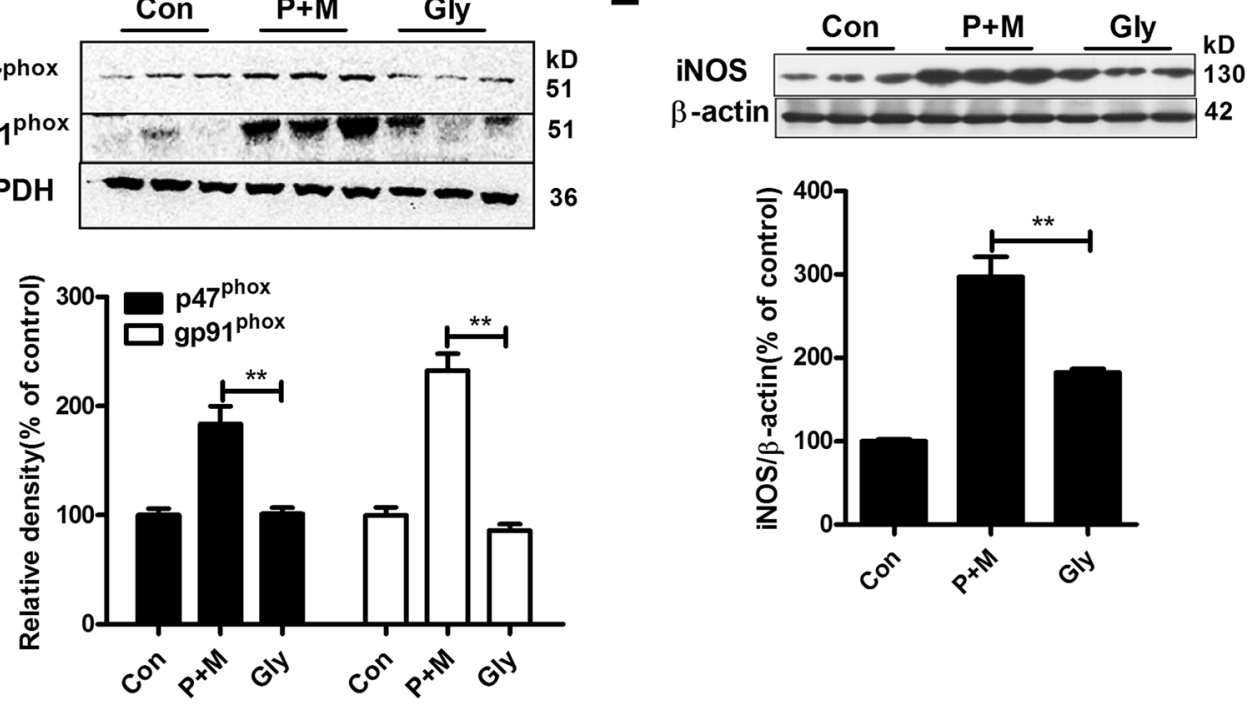

Fig. 7 Glybenclamide mitigates $P+$ M-induced oxidative stress in mice. $\mathbf{a}$ The production of ROS was determined by using DC-FDA probe. $n=4$. b, c The expressions of 4-HNE were determined in the brainstem of $\mathrm{P}+\mathrm{M}$-treated mice with or without glybenclamide by Western blot, and the density of blots was quantified. $\mathbf{d}$, e The expressions of NOX2 subunits (gp91 ${ }^{\text {phox }}$ and p4 $7^{\text {phox }}$ ) and iNOS were determined in the brainstem of $\mathrm{P}+\mathrm{M}$ treated mice with or without glybenclamide by Western blot using specific antibodies, and the density of blots was quantified. $n=6$ for each group. ${ }^{*} p<0.05 .{ }^{* *} p<0.01$ 


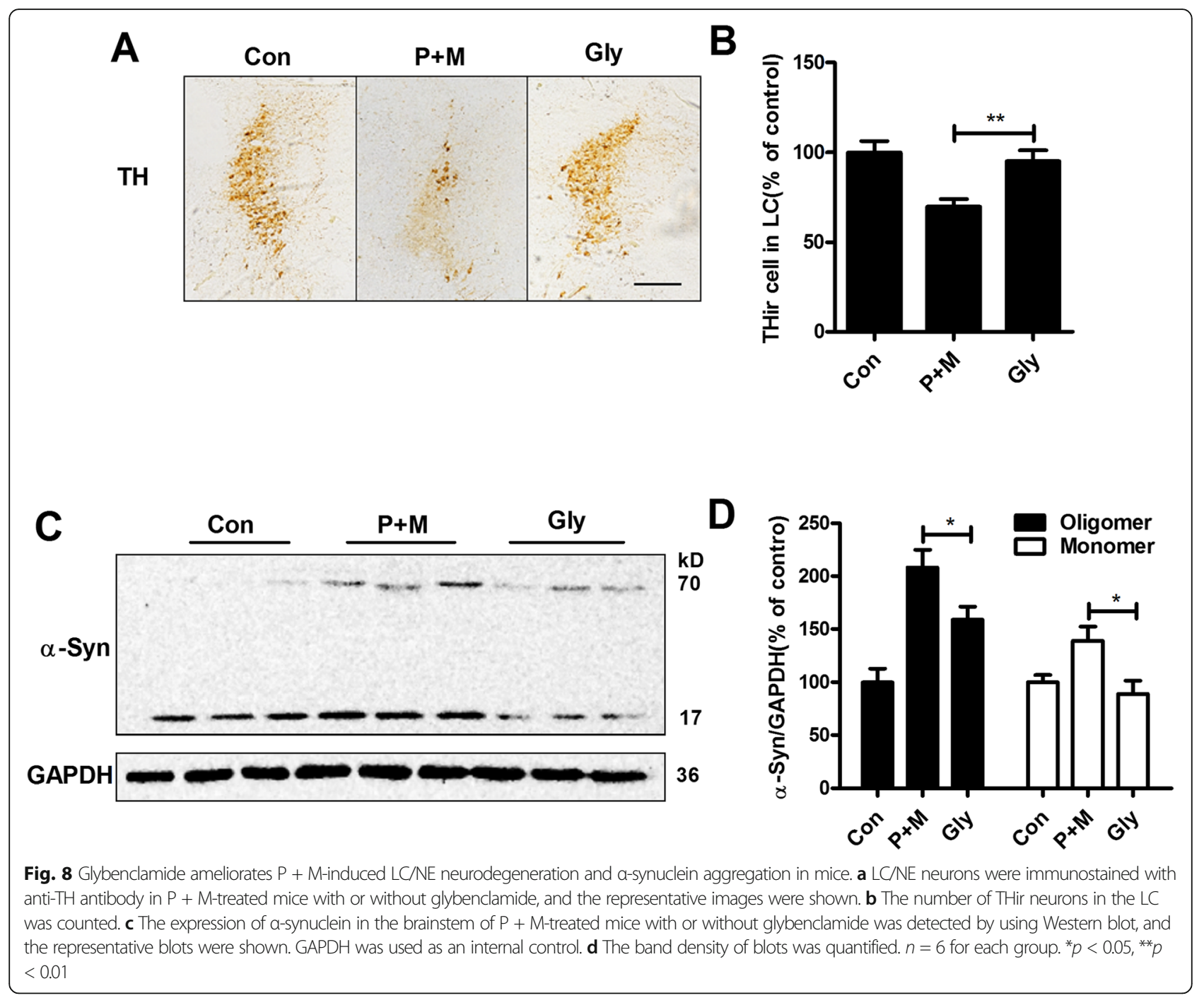

symptoms, such as learning and memory deficits, in these two models [40]. However, the potential mechanisms for $\mathrm{LC} / \mathrm{NE}$ neurodegeneration in PD remained to be determined. In this study, by using $\mathrm{P}+\mathrm{M}$-induced mouse $\mathrm{PD}$ model, we found that CD11b-mediated NLRP3 inflammasome activation and subsequent microglial proinflammatory activation as well as oxidative damage contributed to LC/NE neurodegeneration in PD (Fig. 9).

Microglia-mediated neuroinflammation might be involved in the regulatory effects of CD11b on LC/NE neurodegeneration. Microglial activation and accumulation of proinflammatory factors are observed in the brain, including LC region, in PD patients [41]. In vitro studies showed that depletion of microglia in primary midbrain neuron-glia culture is able to attenuate dopaminergic neurodegeneration induced by LPS, $\mathrm{MPP}^{+}$, rotenone, and paraquat; four toxins often used to create PD models [15, 42, 43]. We recently reported that microglia are activated in the LC in $\mathrm{P}+\mathrm{M}$-treated mice
$[22,30]$. Inhibition of microglia-mediated neuroinflammation by taurine, a sulfur-containing free amino acid, ameliorates the loss of LC/NE neurons in this mouse PD model [30], indicating a detrimental role of microgliamediated neuroinflammation in LC/NE neurodegeneration in PD. In the present study, we found that CD11b deficiency significantly suppressed microglial activation and gene expressions of proinflammatory factors in the brainstem in $\mathrm{P}+\mathrm{M}$-treated mice, suggesting that $\mathrm{CD} 11 \mathrm{~b}$ mediates $\mathrm{P}+\mathrm{M}$-induced LC/NE neurodegeneration by augmenting microglia-mediated neuroinflammation. Similar to our study, Gao et al. reported that genetic ablation of CD11b mitigates HMGB1 microglial activation, $\mathrm{NF}-\kappa \mathrm{B}$ activation, and production of multiple inflammatory and neurotoxic factors in primary neuron-glial cultures [15]. Furthermore, inhibition of CD11b by a blocking antibody also blocks diesel exhaust particleinduced microglial activation, $\mathrm{H}_{2} \mathrm{O}_{2}$ production, and neurodegeneration in vitro [15]. 

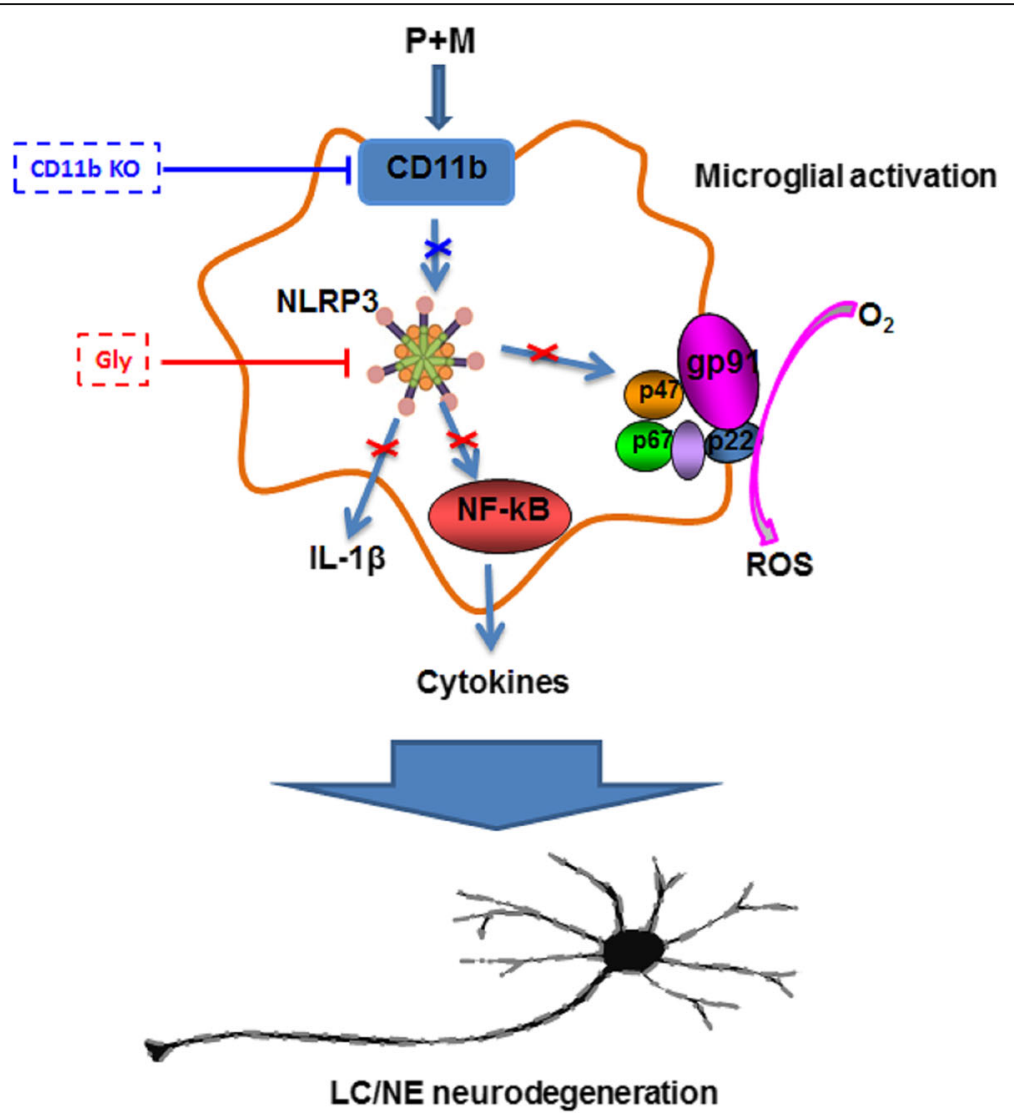

Fig. 9 Proposed model showing how CD11b mediates $P+$ M-induced LC/NE neurodegeneration. $P+M$ exposure in mice elevates CD11b expression in the LC. Genetic deletion of CD11b attenuates P + M-induced LC/NE neurodegeneration, indicating a CD11b-dependent pathway. Our results show that CD11b mediates NLRP3 inflammasome activation in P + M-treated mice. Inhibition of NLRP3 inflammasome by glybenclamide suppresses P + M-induced microglial proinflammatory activation and NADPH oxidase activation as well as ROS production, which are associated with LC/NE neuroprotection

Mechanistically, the most critical question to address is how CD11b regulates microglia-mediated neuroinflammation. NLRP3 inflammasome is an intracellular multiprotein complex composed of the NLRP3 scaffold, apoptosis-associated speck-likeprotein (ASC) adaptor, and procaspase-1. NLRP3 inflammasome can sense damage associated molecular patterns (DAMPs) and become activated, leading to activation of caspase- 1 and secretion of some proinflammatory cytokines, such as IL-1 $\beta$ and IL-18 [44-46]. Strong evidence suggested that the activation of NLRP3 inflammasome is a key factor to regulate microglial activation in neurodegenerative diseases [47]. Heneka et al. reported that genetic inactivation of NLRP3 attenuates microglial activation and proinflammatory factors production in APP/PS1 mouse AD model [48]. In MPTP-induced mouse PD model, Lee et al. found that genetic inactivation of NLRP3 abolishes MPTP-induced microglial activation, recruitment, and IL- $1 \beta$ production in the subsantia nigra of mouse brain [49]. Furthermore, pharmacological inhibition of NLRP3 inflammasome also displays potent inhibitory effects on microglial activation in 6-OHDA and $\alpha$-synuclein rodent PD models [33]. Consistent with these reports, NLRP3 inflammasome activation was observed in $\mathrm{P}+\mathrm{M}$-treated mice. CD11b deficiency greatly reduced $\mathrm{P}+\mathrm{M}$-induced activation of NLRP3 inflammasome. Furthermore, inhibition of NLRP3 inflammasome by glybenclamide abrogated P + M-induced microglial proinflammatory activation. Glybenclamide also prevented oxidative stress and expressions of NOX2 and iNOS, two enzymes responsible for superoxide and RNS production, respectively, during neuroinflammation. More importantly, inhibition of NLRP3 inflammasome by glybenclamide was associated ameliorated LC/NE neurodegeneration and $\alpha$-synuclein aggregation in $\mathrm{P}+\mathrm{M}$-injected mice. These results suggest that NLRP3 inflammasome may be a key factor for CD11b-mediated microglial activation and subsequent LC/NE neurodegeneration. Notably, the mechanisms behind how CD11b regulates NLRP3 inflammasome activation remain to be investigated in the present study, further research focusing on this point should be guaranteed in the future. 


\section{Conclusions}

In summary, our findings reveal a novel role of CD11b in LC/NE neurodegeneration through NLRP3 inflammasomedependent microglial proinflammatory activation and oxidative stress in a two pesticide-induced mouse PD model, providing a novel insight for the immunopathogenesis of $\mathrm{LC} / \mathrm{NE}$ neuronal damage in PD. Our study also suggests that CD11b might be a promising target for the development of therapeutic agents combating LC/NE neurodegeneration in patients suffering from this disorder.

\section{Abbreviations}

A $\beta$ : $\beta$-amyloid; AD: Alzheimer disease; ASC: Apoptosis-associated specklikeprotein; CNS: Central nervous system; DAMPs: Damage associated molecular patterns; DSP-4: N-(2-Chloroethyl)-N-ethyl-2-bromobenzylamine; 4HNE: 4-Hydroxynonenal; Iba-1: Ionized calcium binding adaptor molecule-1; IL-1及: Interleukin-1 $\beta$; LC/NE: Locus coeruleus noradrenergic: LPS: Lipopolysaccharide; MCAO: Middle cerebral artery occlusion; MDA: Malondialdehyde; MPTP: 1-Methyl-4-phenyl-1,2,3,6-tetrahydropyridine; NLRP3: NLR family pyrin domain containing 3; PD: Parkinson's disease; PMA: Phorbol myristate acetate; TH: Tyrosine hydroxylase; THir: THimmunoreactive; TNFa: Tumor necrosis factor a; WT: wild type

\section{Acknowledgements}

Not applicable.

\section{Authors' contributions}

$\mathrm{LH}, \mathrm{XQ}$, and $\mathrm{RH}$ performed the research. $\mathrm{LH}$ and $\mathrm{XQ}$ analyzed the data. $\mathrm{LH}$, $X Z$, and $Q W$ designed the research. $L H$ and $X Q$ wrote the first draft of the paper. XZ and QW edited the paper. All authors read and approved the manuscript.

\section{Funding}

This work was supported by National Natural Science Foundation of China (81973087; 81703264; 81872654), Liaoning Provincial Natural Science Foundation of China (2019-MS-077), LiaoNing Revitalization Talents Program (XLYC1907026), Liaoning BaiQianWan Talents Program (No. [2017]90), and "QiZhen" talent project of Dalian Medical University (No. 201122).

\section{Availability of data and materials}

All data generated or analyzed during this study are included in this published article [and its supplementary information files].

\section{Ethics approval and consent to participate}

All animal procedures and their care were carried out in accordance the National Institute of Health Guide for the Care and Use of Laboratory Animals and were approved by the Institutional Animal Care and Use Committee of Dalian Medical University.

\section{Consent for publication}

Not applicable.

\section{Competing interests}

The authors declare that they have no competing interests.

\section{Author details}

${ }^{1}$ School of Public Health, Dalian Medical University, Dalian 116044, China. ${ }^{2}$ Department of Clinical Nutrition, Second Affiliated Hospital of Dalian Medical University, Dalian 116023, China. ${ }^{3}$ Qingdao Municipal Center for Disease Control \& Prevention/Qingdao Institute of Preventive Medicine, Qingdao 266033, China. ${ }^{4}$ School of Public Health, Cheeloo College of Medicine, Shandong University, Jinan 250012, China. ${ }^{5}$ National-Local Joint Engineering Research Center for Drug-Research and Development (R \& D) of Neurodegenerative Diseases, Dalian Medical University, Dalian 116044, China.
Received: 15 September 2019 Accepted: 22 April 2020

Published online: 06 May 2020

\section{References}

1. Espay AJ, LeWitt PA, Kaufmann H. Norepinephrine deficiency in Parkinson's disease: the case for noradrenergic enhancement. Mov Disord. 2014;29: 1710-9.

2. Berridge $\mathrm{CW}$, Waterhouse $\mathrm{BD}$. The locus coeruleus-noradrenergic system: modulation of behavioral state and state-dependent cognitive processes. Brain Res Brain Res Rev. 2003;42:33-84.

3. Vermeiren Y, De Deyn PP. Targeting the norepinephrinergic system in Parkinson's disease and related disorders: the locus coeruleus story. Neurochem Int. 2017;102:22-32.

4. Theofilas P, Ehrenberg AJ, Nguy A, Thackrey JM, Dunlop S, Mejia MB, Alho AT, Paraizo Leite RE, Rodriguez RD, Suemoto CK, et al. Probing the correlation of neuronal loss, neurofibrillary tangles, and cell death markers across the Alzheimer's disease Braak stages: a quantitative study in humans. Neurobiol Aging. 2018;61:1-12.

5. Braak H, Del Tredici K, Rub U, de Vos RA, Jansen Steur EN, Braak E. Staging of brain pathology related to sporadic Parkinson's disease. Neurobiol Aging. 2003;24:197-211.

6. Zarow C, Lyness SA, Mortimer JA, Chui HC. Neuronal loss is greater in the locus coeruleus than nucleus basalis and substantia nigra in Alzheimer and Parkinson diseases. Arch Neurol. 2003:60:337-41.

7. Song S, Jiang L, Oyarzabal EA, Wilson B, Li Z, Shih YI, Wang Q, Hong JS. Loss of brain norepinephrine elicits neuroinflammation-mediated oxidative injury and selective caudo-rostral neurodegeneration. Mol Neurobiol. 2019;56: 2653-69.

8. Jiang L, Chen SH, Chu CH, Wang SJ, Oyarzabal E, Wilson B, Sanders V, Xie K, Wang Q, Hong JS. A novel role of microglial NADPH oxidase in mediating extra-synaptic function of norepinephrine in regulating brain immune homeostasis. Glia. 2015;63:1057-72.

9. Yao N, Wu Y, Zhou Y, Ju L, Liu Y, Ju R, Duan D, Xu Q. Lesion of the locus coeruleus aggravates dopaminergic neuron degeneration by modulating microglial function in mouse models of Parkinsons disease. Brain Res. 2015; 1625:255-74.

10. Abram $\mathrm{CL}$, Lowell CA. The ins and outs of leukocyte integrin signaling. Annu Rev Immunol. 2009;27:339-62.

11. Erdei A, Lukacsi S, Macsik-Valent B, Nagy-Balo Z, Kurucz I, Bajtay Z. Nonidentical twins: different faces of CR3 and CR4 in myeloid and lymphoid cells of mice and men. Semin Cell Dev Biol. 2019;85:110-21.

12. Lishko VK, Yakubenko VP, Ugarova TP, Podolnikova NP. Leukocyte integrin Mac-1 (CD11b/CD18, alphaMbeta2, CR3) acts as a functional receptor for platelet factor 4. J Biol Chem. 2018;293:6869-82.

13. Hong S, Beja-Glasser VF, Nfonoyim BM, Frouin A, Li S, Ramakrishnan S, Merry KM, Shi Q, Rosenthal A, Barres BA, et al. Complement and microglia mediate early synapse loss in Alzheimer mouse models. Science. 2016;352:712-6.

14. Zhou H, Liao J, Aloor J, Nie H, Wilson BC, Fessler MB, Gao HM, Hong JS. CD11b/CD18 (Mac-1) is a novel surface receptor for extracellular doublestranded RNA to mediate cellular inflammatory responses. J Immunol. 2013; 190:115-25

15. Gao HM, Zhou H, Zhang F, Wilson BC, Kam W, Hong JS. HMGB1 acts on microglia Mac1 to mediate chronic neuroinflammation that drives progressive neurodegeneration. J Neurosci. 2011;31:1081-92.

16. Hu X, Zhang D, Pang H, Caudle WM, Li Y, Gao H, Liu Y, Qian L, Wilson B, Di Monte DA, et al. Macrophage antigen complex-1 mediates reactive microgliosis and progressive dopaminergic neurodJ Immunolegeneration in the MPTP model of Parkinson's disease. 2008;181:7194-204.

17. Zhang D, Hu X, Qian L, Chen SH, Zhou H, Wilson B, Miller DS, Hong JS. Microglial MAC1 receptor and PI3K are essential in mediating beta-amyloid peptide-induced microglial activation and subsequent neurotoxicity. J Neuroinflammation. 2011;8:3.

18. Czirr E, Castello NA, Mosher Kl, Castellano JM, Hinkson IV, Lucin KM, BaezaRaja B, Ryu JK, Li L, Farina SN, et al. Microglial complement receptor 3 regulates brain Abeta levels through secreted proteolytic activity. J Exp Med. 2017;214:1081-92.

19. Su EJ, Cao C, Fredriksson L, Nilsson I, Stefanitsch C, Stevenson TK, Zhao J, Ragsdale M, Sun YY, Yepes M, et al. Microglial-mediated PDGF-CC activation increases cerebrovascular permeability during ischemic stroke. Acta Neuropathol. 2017;134:585-604. 
20. Hou L, Bao X, Zang C, Yang H, Sun F, Che Y, Wu X, Li S, Zhang D, Wang Q. Integrin CD11b mediates alpha-synuclein-induced activation of NADPH oxidase through a Rho-dependent pathway. Redox Biol. 2018;14:600-8.

21. Hou L, Wang K, Zhang C, Sun F, Che Y, Zhao X, Zhang D, Li H, Wang Q. Complement receptor 3 mediates NADPH oxidase activation and dopaminergic neurodegeneration through a Src-Erk-dependent pathway. Redox Biol. 2018;14:250-60

22. Hou L, Zhang C, Wang K, Liu X, Wang H, Che Y, Sun F, Zhou X, Zhao X, Wang $Q$. Paraquat and maneb co-exposure induces noradrenergic locus coeruleus neurodegeneration through NADPH oxidase-mediated microglial activation. Toxicology. 2017;380:1-10.

23. Zhang W, Xu X, Kao R, Mele T, Kvietys P, Martin CM, Rui T. Cardiac fibroblasts contribute to myocardial dysfunction in mice with sepsis: the role of NLRP3 inflammasome activation. PLoS One. 2014;9:e107639.

24. Wang Q, Chu CH, Qian L, Chen SH, Wilson B, Oyarzabal E, Jiang L, Ali S, Robinson B, Kim HC, Hong JS. Substance P exacerbates dopaminergic neurodegeneration through neurokinin-1 receptor-independent activation of microglial NADPH oxidase. J Neurosci. 2014;34:12490-503.

25. Wang Q, Qian L, Chen SH, Chu CH, Wilson B, Oyarzabal E, Ali S, Robinson B, Rao D, Hong JS. Post-treatment with an ultra-low dose of NADPH oxidase inhibitor diphenyleneiodonium attenuates disease progression in multiple Parkinson's disease models. Brain. 2015;138:1247-62.

26. Wang Q, Shin EJ, Nguyen XK, Li Q, Bach JH, Bing G, Kim WK, Kim HC, Hong JS. Endogenous dynorphin protects against neurotoxin-elicited nigrostriatal dopaminergic neuron damage and motor deficits in mice. J

Neuroinflammation. 2012;9:124

27. Zhang W, Wang T, Qin L, Gao HM, Wilson B, Ali SF, Hong JS, Liu B. Neuroprotective effect of dextromethorphan in the MPTP Parkinson's disease model: role of NADPH oxidase. FASEB J. 2004;18:589-91.

28. Paxinos G, Franklin KBJ: The mouse brain in stereotaxic coordinates. second edn: Academic Press, San Diego.; 2001.

29. Che Y, Hou L, Sun F, Zhang C, Liu X, Piao F, Zhang D, Li H, Wang Q. Taurine protects dopaminergic neurons in a mouse Parkinson's disease model through inhibition of microglial M1 polarization. Cell Death Dis. 2018:9:435.

30. Hou L, Che Y, Sun F, Wang Q. Taurine protects noradrenergic locus coeruleus neurons in a mouse Parkinson's disease model by inhibiting microglial M1 polarization. Amino Acids. 2018;50:547-56.

31. Hou L, Sun F, Huang R, Sun W, Zhang D, Wang Q. Inhibition of NADPH oxidase by apocynin prevents learning and memory deficits in a mouse Parkinson's disease model. Redox Biol. 2019;22:101134.

32. Long J, Wang Q, He H, Sui X, Lin G, Wang S, Yang J, You P, Luo Y, Wang Y. NLRP3 inflammasome activation is involved in trimethyltin-induced neuroinflammation. Brain Res. 2019:1718:186-93.

33. Borel F, Gernoux G, Sun H, Stock R, Blackwood M, Brown RH Jr, Mueller C. Safe and effective superoxide dismutase 1 silencing using artificial microRNA in macaques. Sci Transl Med. 2018;10:eaau6414.

34. Orihuela R, McPherson CA, Harry GJ. Microglial M1/M2 polarization and metabolic states. Br J Pharmacol. 2016;173:649-65.

35. Huang M, Li Y, Wu K, Yan W, Tian T, Wang Y, Yang H. Paraquat modulates microglia M1/M2 polarization via activation of TLR4-mediated NF-kappaB signaling pathway. Chem Biol Interact. 2019;310:108743.

36. Taetzsch T, Levesque S, McGraw C, Brookins S, Luqa R, Bonini MG, Mason RP, Oh U, Block ML. Redox regulation of NF-kappaB p50 and M1 polarization in microglia. Glia. 2015;63:423-40.

37. Bermudez S, Khayrullina G, Zhao Y, Byrnes KR. NADPH oxidase isoform expression is temporally regulated and may contribute to microglial/ macrophage polarization after spinal cord injury. Mol Cell Neurosci. 2016;77: 53-64.

38. Mander P, Brown GC. Activation of microglial NADPH oxidase is synergistic with glial iNOS expression in inducing neuronal death: a dual-key mechanism of inflammatory neurodegeneration. J Neuroinflammation. 2005;2:20.

39. Gao HM, Zhang F, Zhou H, Kam W, Wilson B, Hong JS. Neuroinflammation and alpha-synuclein dysfunction potentiate each other, driving chronic progression of neurodegeneration in a mouse model of Parkinson's disease. Environ Health Perspect. 2011;119:807-14.

40. Song S, Wang Q, Jiang L, Oyarzabal E, Riddick NV, Wilson B, Moy SS, Shih YI, Hong JS. Noradrenergic dysfunction accelerates LPS-elicited inflammationrelated ascending sequential neurodegeneration and deficits in non-motor/ motor functions. Brain Behav Immun. 2019:374.

41. Imamura K, Hishikawa N, Sawada M, Nagatsu T, Yoshida M, Hashizume Y. Distribution of major histocompatibility complex class II-positive microglia and cytokine profile of Parkinson's disease brains. Acta Neuropathol. 2003; 106:518-26.

42. Wang T, Zhang W, Pei Z, Block M, Wilson B, Reece JM, Miller DS, Hong JS. Reactive microgliosis participates in MPP+-induced dopaminergic neurodegeneration: role of $67 \mathrm{kDa}$ laminin receptor. Faseb j. 2006;20:906-15.

43. Wu XF, Block ML, Zhang W, Qin L, Wilson B, Zhang WQ, Veronesi B, Hong JS. The role of microglia in paraquat-induced dopaminergic neurotoxicity. Antioxid Redox Signal. 2005;7:654-61.

44. Hong P, Gu RN, Li FX, Xiong XX, Liang WB, You ZJ, Zhang HF. NLRP3 inflammasome as a potential treatment in ischemic stroke concomitant with diabetes. J Neuroinflammation. 2019;16:121.

45. Swanson KV, Deng M, Ting JP. The NLRP3 inflammasome: molecular activation and regulation to therapeutics. Nat Rev Immunol. 2019;19:477-89.

46. He Y, Hara H, Nunez G. Mechanism and regulation of NLRP3 inflammasome activation. Trends Biochem Sci. 2016:41:1012-21.

47. Heneka MT, McManus RM, Latz E. Inflammasome signalling in brain function and neurodegenerative disease. Nat Rev Neurosci. 2018;19:610-21.

48. Heneka MT, Kummer MP, Stutz A, Delekate A, Schwartz S, Vieira-Saecker A, Griep A, Axt D, Remus A, Tzeng TC, et al. NLRP3 is activated in Alzheimer's disease and contributes to pathology in APP/PS1 mice. Nature. 2013;493: 674-8.

49. Lee E, Hwang I, Park S, Hong S, Hwang B, Cho Y, Son J, Yu JW. MPTP-driven NLRP3 inflammasome activation in microglia plays a central role in dopaminergic neurodegeneration. Cell Death Differ. 2019;26:213-28.

\section{Publisher's Note}

Springer Nature remains neutral with regard to jurisdictional claims in published maps and institutional affiliations.

Ready to submit your research? Choose BMC and benefit from:

- fast, convenient online submission

- thorough peer review by experienced researchers in your field

- rapid publication on acceptance

- support for research data, including large and complex data types

- gold Open Access which fosters wider collaboration and increased citations

- maximum visibility for your research: over $100 \mathrm{M}$ website views per year

At BMC, research is always in progress.

Learn more biomedcentral.com/submissions 